EGU21-13085

EGU General Assembly 2021

(c) Author(s) 2021. This work is distributed under

the Creative Commons Attribution 4.0 License.

\title{
Water Sensitive Cities: integrated approach to enhance urban flood resilience in Parma (Northen Italy)
}

\author{
Arianna Dada ${ }^{1}$, Christian Urich ${ }^{2}$, Michèle Pezzagno ${ }^{1}$, and Giovanna Grossi ${ }^{1}$ \\ ${ }^{1}$ Università degli Studi di Brescia, DICATAM - Dep. of Civil, Environmental, Architectural Engineering and Mathematics, \\ Brescia, Italy (a.dada@unibs.it) \\ ${ }^{2}$ Monash University of Melbourne, Department of Civil Engineering, Addess: Wellington Road, Victoria 3800, Australia.
}

The climate change of the last half century is globally causing an increasingly in violent meteorological phenomena. Cities are experiencing the pressures of these phenomena and they are facing many challenges - economic, social, health and environmental.

Over the coming decades the population growth and the rapid urbanization will bring to a tumultuous growth of the cities that will become more and more vulnerable, especially to flood hazards.

In order to make our urban water systems more effective to these challenges new water management strategies must be developed. The complexity of this challenge calls for the integration of knowledge from different disciplines and collaborative approaches.

The concept of Water Sensitive Cities is one of the starting points for developing new techniques, strategies, policies, and tools to ensure a better liveability, sustainability, and resilience of the cities.

In this study, the DAnCE4Water model to promote the development of Water Sensitive Cities, was applied to Parma, an Italian town that faced serious water issues in the last years. Through the model the efficiency of new decentralized technologies, as green roofs and porous pavement, and their integration with the existing centralized technologies (sewerage), was estimated.

The first phase of the study concerned the analysis of the current state of the sewerage network and the relative critical issues. Flow rates and the amount of surface runoff were calculated using the SWMM modelling software.

In the second phase three hypothetical different scenarios were created by adopting different intervention strategies. The first scenario was created by using green roofs for a percentage of existing buildings in the urban area equal to 30\%; the second scenario was created by adopting the porous pavement technology. For the third scenario, a possible urban development was simulated, with its consequent population, without adopting any flood risk mitigation strategy. A hydraulic study was carried out for each scenario highlighting the differences in terms of runoff formation and percentage of infiltration. 
The integrated approach enables a city to test its current water management practices and policy, it helps cities to identify their short and long term goals to enhance water sensitivity, it gives a quantification of benefits and costs and it provides an estimate, still in the design phase, of the effectiveness of possible strategies under different scenarios like climate changes, changes in the societal needs and urban changes by modelling the complex dynamics between societal system, urban environment and the urban water system. 